\title{
Strategic Change Management Practices on Performance of Savings and Credit Cooperative Societies in Kiambu County, Kenya
}

\author{
Kaberi Lawrence', Patricia Kung' ${ }^{\mathbf{2}}$,

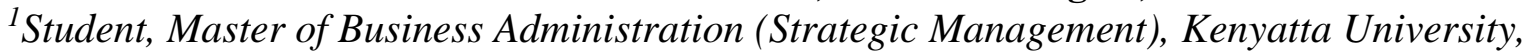 \\ Kenya \\ ${ }^{2}$ Lecturer, Department of Business Administration, Kenyatta University, Kenya
}

\begin{abstract}
Achieving success in performance is a key objective in all organizations globally. Performance is crucial since it determines the future sustainability of the business. However, Savings and Credit Cooperative Organizations (SACCOs) are experiencing performance challenges while operating under an unpredictable environment. In the year 2019, 86\% of the SACCOs in Kenya registered a decline of $12 \%$ and $15 \%$ in their cashflows and profitability, respectively. In addition, $37 \%$ of the loss making SACCOs have witnessed panic withdrawals leading to cashflow crunches and collapse. As a response to this scenario, SACCOs have implemented strategic change management practices to increase the chance of successful performance in an unpredictable operating environment. This study therefore sought to establish the impact of strategic change management practices on performance. The study's general objective was to assess the influence of strategic change management practices on performance of SACCOs in Kiambu County, Kenya. The specific objectives were to determine the influence of corporate communication, strategic supervision, strategic target-setting and strategic resource allocation on the performance of SACCOs in Kiambu County, Kenya. The study was based on the dynamic capabilities theory which was complemented by Kotters theory, nudge theory, and resource-based view theory. The study utilized descriptive research design. The unit of analysis was the 14 DT-SACCOs with their head offices registered in Kiambu County. The unit of observation were five departmental managers involved in strategic change initiatives in each of the 14 SACCOs which translated to 70 respondents. The population of study was not sampled due to the small number of respondents. Primary data was collected through structured questionnaires. Secondary data was collected through a data collection sheet. To minimize ambiguities in the questionnaire, the study tested for validity using criterion predictive validity model. The reliability for the study was attained by computing the Cronbach's alpha coefficient. Pilot study was conducted using seven respondents from Mhasibu SACCO in Nairobi County which neighbors Kiambu County. The administration and collection of data was conducted through drop-and-pick-later method. Data analysis was conducted using descriptive and inferential statistics. The presentation of data took various forms including comparative tables, percentages, frequencies, and charts. The study found that there is a positive and significant relationship between corporate communication, strategic supervision, strategic target setting, strategic resource allocation and organizational performance. The study recommends that SACCOs top leadership adopts and trains its employees on effective resource management. This would ensure that resource allocation is done in a manner that is strategic and keeps on improving the performance of the SACCOs. It's also recommended that measures be put in place to enable employees to set strategic targets that are realistic and achievable to enable the SACCOs to realize improvement in performance.
\end{abstract}

Key Words: Change Management Practices, Organization Strategic Orientation, SACCOs

DOI 10.35942/ jbmed.v4i1.228 
International Journal of Business Management, Entrepreneurship and Innovation, Volume 4, Issue 1, 2022, PP 20-35, ISSN 2707-8027

BMED

\section{Cite this Article:}

Kaberi, L., \& Kung'u, P. (2022). Strategic Change Management Practices on Performance of Savings and Credit Cooperative Societies in Kiambu County, Kenya. International Journal of Business Management, Entrepreneurship and Innovation, 4(1), 20-35. https://doi.org/10.35942/jbmed.v4i1.228

\subsection{Introduction}

Globally, it is a commonplace observation that organizations are experiencing inconsistent performance due to the unpredictable operating environment. Most organizations across various industries are collapsing and some are operating on the edge of collapsing, and performance standards for most of them have been found to be below par (Pearce \& Robinson, 2017). SACCOs in particular have experienced declining cashflows, profitability, assets, amount of loans advanced to customers, and an increase in amounts of non-performing loans. Strategic change management practices have proven to be vital in influencing organizational performance by setting up adaptive strategies that ensure organizational resilience. The variables of focus regarding strategic change management include corporate communication, strategic supervision, strategic target setting, and strategic resource allocation. Strategic change management practices enable organizations to align their actions to current and future environmental demands to ensure business continuity and sustainable profitability (Al-Kandi Asutay \& Dixon, 2016). Generally, on the organizations' external environment, they have limited influence, their focus tends to be to identify internal constraints inhibiting rapid response into market opportunities and challenges and to identify critical interventions in addressing these issues affecting performance (Alfred, 2016).

The success of an organization is measured using its performance. Organizations that achieve their set performance goals are said to perform better than those that do not. Successful organizations have been reported to formulate comprehensive strategies that allow them to achieve their objectives (Greenwood \& Hinnings, 2017). Organizations are continuously becoming aware that change cannot be avoided (Ocasio et al., 2018). In fact, most organizations acknowledge this fact and prepare adequately for change. Akter et al. (2016) mentioned that an organization's response to change would affect its performance. Organizations that implement changes effectively and efficiently have been reported to perform better than those that do not. Change has recently become so vital and has become a research key subject. The aspect of strategic change management practices is a product of continued research on change and how firms can comprehensively undertake it. Wiedner et al. (2017), Ocasio et al. (2018), Almansoori (2019) and Karani (2016) mentioned that strategic change management practices could either be drawn from the models put forward to assist the change process or from highly researched practices.

The first option draws its practices from various change management models like Kubler-Ross model, Kotter's model, , ADKAR model or Lewin's model. The other sources of strategic change management practices are widely researched individual practices. Whichever the source of the practices, Karani (2016) asserted that importance should lie in the fact that these are predetermined set of procedures that should assist organizations in responding to change effectively and efficiently to promote not only performance but also growth. The performance of SACCOs has been adversely affected by many unending challenges. In responding to the external environment, the challenges require adjustment of the strategy to achieve performance goals or change the organization's mission statement. To adjust the strategies involves change in the fundamental approach of doing business i.e the product kinds and how to sell them, the markets targeted, 
International Journal of Business Management, Entrepreneurship and Innovation, Volume 4, Issue 1, 2022, PP 20-35, ISSN 2707-8027

\section{BMET}

partnerships, the regional or local activity level, overall strategic orientation, or joint arrangements in business to be pursued.

Such changes are intended to assist the SACCOs attain the desired performance in terms of total assets, amount of loans advanced to customers, non-performing loans' performance to total loans advanced, customer deposit amounts and, number of operating SACCOs. With the evolving nature of the dynamic Kenyan business environment, the SACCOs in Kenya, and particularly in Kiambu County must deal with proper strategic change management practices owing to their poor, inconsistent and unstable performance over the years. Strategic change management practices align organizations to their current and future environments, enabling them to meet stakeholder interests. Wiedner et al. (2017) defined strategic change management practice as part of managerial actions and decisions taken on by an organization to withstand the internal and external organizational environments' changes. Similarly, Ocasio et al. (2018) mentioned that strategic management practices are those actions that are designed to framework an organization's activities, pinpoint the strategies to be used to compete effectively and how to organize those activities systematically. Different scholars have varied views on strategic change management practices, with some such as Wiedner et al. (2017) and Ocasio et al. (2018) opting for stages in change management models while others such as Almansoori (2019) and Karani (2016) use specific strategies informed by studied practice. This study opted for the latter in which the main strategic management practices were listed as corporate communication, strategic supervision, strategic resource allocation, and strategic target setting. In any organization, supervision is key in implementing any changes. Helfat and Martin (2015) further opined that for successful change to be realized by the organization, it has to originate from that organization's leadership who are accountable for performance.

Strategic supervision in the context of this study will be measured by evaluation of performance against intended outcome, identification of root cause of performance gaps and implementation of corrective action. Strategic target setting among the principal individuals affected by the organization's changes is critical. Strategic resource allocation refers to the practice of properly allocating resources of an organization to realize the intended outcome. Therefore, the major indicators that will be used to measure strategic resource allocation are established criteria for resource allocation, budgeting of available resources, and tracking utilization of resources. A study by Kafashpoor, Shakoori and Sadeghian (2016) found a direct link between resource allocation and organizational performance explicitly by indicating that the former significantly affects the latter. "Strategic target setting is a core activity that needs to be accorded adequate attention since it supports strategic change management's other functionalities." Within the confines of this study, strategic target setting will be approached by examining core indicators which include short, medium, long-range targets, employee involvement in setting targets and, rewards and incentive schemes. Individual performance level increase with use of target setting (Bronkhorst, Steijn \& Vermeeren, 2015). The last critical practice is strategic communication which is involved in almost every aspect of change practices. Effective communication allows the leadership, stakeholders, and employees to be at par in matters of change (Greenwood \& Hinnings, 2017). On the other hand, poor communication may result in unsuccessful change implementation that may be detrimental to the organization's survival. 
International Journal of Business Management, Entrepreneurship and Innovation, Volume 4, Issue 1, 2022, PP 20-35, ISSN 2707-8027

IBMED

According to the definition by SACCO Societies Regulatory Authority (SASRA) "a SACCO is a people's independent association who are voluntarily united together with the aim of meeting their common social economic, cultural, and social ambitions and needs through a joint-ownership and controlled entity." Usually, a SACCO does not belong to any person, but to members who take part democratically in the administration and management of the organization (Mango, 2017). SACCOS in Kenya are regulated by SASRA which was established under the new constitution. According to the SASRA supervision annual report for year 2019, there are 157 DT - SACCOS registered by SASRA in Kenya 14 of which have their head offices/quarters in Kiambu County. Over the years, SACCOs' core business was known for savings and giving loans. Changes in the environment have seen this transition to various services and products including professional investment advice, , transport industry and investment in real estate. This has continued to boost the rating of SACCOs as a competitor in the financial sector. Different product range are offered in Kiambu County SACCOs e.g mortgages, personal and business loans, savings, money transfers, payment services and insurance. SACCOs in Kiambu county have experienced unstable performance over the years as confirmed by the SASRA reports. SASRA seeks to build top notched SACCO sector to meet the ever-changing demands through prudential regulation by benchmarking worldwide SACCOS that run credit unions through implementation of internationally recognized prudential standards (SASRA, 2016).

\subsection{Statement of the Problem}

Kenyan SACCOs are experiencing performance challenges while operating under an unpredictable environment. According to the SASRA, the performance of SACCOs regarding measures such as total assets, amount of loans advanced to customers, percentage of nonperforming loans to total loans advanced, amount of customer deposits, and operating cashflow has declining. In the year 2019, $86 \%$ of SACCOs in Kenya registered a $12 \%$ and $15 \%$ decline in their cashflows and profitability, respectively. About $37 \%$ of the loss making SACCOs have witnessed panic withdrawals leading to cash crunches and collapse. A survey by SASRA in year 2019 indicated that investor confidence in SACCOs has declined by $17 \%$ thus putting the stability of the DT-SACCO subsector at risk. The various causes of declining performance, cited by stakeholders, include mismanagement, fraud and bad loans, poor lending, and debt collection measures etc. The performance in a demanding and unpredictable external environment has led SACCOs to adjust their strategies. Adjusting the SACCOs strategies has involved changing the fundamental approach of doing business i.e the product kinds and how to sell them, the markets targeted, various partnerships to be pursued and other joint business arrangements. SACCOs have implemented, at various levels, strategic resource allocation, strategic target setting, corporate communication, and strategic supervision.

Various studies have attempted to establish how organizations' performance and strategic change management practices relate. Nyaga \& Gakobo (2017) studied how performance within Kenya's Manufacturing sector was impacted by strategic change management practices. It was established that strategic change and improved performance correlated positively. This study was however undertaken within the manufacturing sector only and therefore its findings might not be applicable in other sectors. Njoroge (2018), in his study on how organizational performance was impacted by strategic change management practices within other authors have discovered insignificant and negative impact in this same context. This points a further need for more research to be conducted to allow sufficient and reliable findings that would draw clear and succinct relationship between these two phenomena. The studies reviewed present a conceptual research gap since they do not 
International Journal of Business Management, Entrepreneurship and Innovation, Volume 4, Issue 1, 2022, PP 20-35, ISSN 2707-8027

\section{BMED}

incorporate strategic change management and performance as independent and dependent variables, respectively. From the analysis above its clear that is not clear whether strategic management practices influence the performance of these firms and that is why we are undertaking the research. Therefore, this study seeks to fill this research gap by responding to following research question: what is the influence of strategic change management practices on Kiambu County SACCOs' performance?

\subsection{Research Objectives}

The general objective of the study was to assess the influence of strategic change management practices on the performance of SACCOs in Kiambu County, Kenya.

The specific objectives were:

i. To determine the influence of corporate communication on the performance of SACCOs in Kiambu County, Kenya.

ii. To examine the influence of strategic supervision on the performance of SACCOs in Kiambu County, Kenya.

iii. To investigate the influence of strategic target-setting on the performance of SACCOs in Kiambu County, Kenya.

iv. To assess the influence of strategic resource allocation on the performance of SACCOs in Kiambu County, Kenya.

\subsection{Literature Review}

\subsection{Theoretical Literature Review}

The study was based on the dynamic capabilities theory which was complemented by Kotters theory, nudge theory and the dynamic capability theory.

\subsubsection{Nudge Theory}

The theory was developed by Daniel Kahneman and Amos Tversky in 1979. The nudge theory is coined from the nudge concept, which suggests indirect suggestions and positive reinforcement as modes to influence individuals or groups' making of decision and behaviors. The theory was brought to prominence by Thaler and Sunstein (2008). The theory advocates for influencing behavior without applying force but by influencing the choices or behaviors of the person where change is needed. A nudge, from its literal meaning, is a reaction to do something. The nudge theory can be used to dictate individuals' or groups' behavior in the occurrence of a particular trigger. Much like nudging, the nudge theory ensures that the group's reaction or individuals is not in a forceful manner but almost natural. Since its formulation, the theory has been used extensively in government, business, and healthcare. Of critical importance is its application in business. It has predominantly been utilized in corporate culture and business management. This area of application of the theory doubles up as its relevance to this study particularly supporting the variables of strategic target setting and strategic supervision. Target setting is crucial as it provides the basis for driving performance. The focus on the desired individual and group behavior/culture speaks to strategic supervision. In the current hyper-dynamic environment in which organizations exist, change is inevitable and is down to 'when' rather than 'if' (Simon \& Tagliabue, 2018). Using the principle behind the nudge theory, SACCOs should formulate practices that will enable the employees to respond accordingly to these changes. Hence the concept of strategic change 
International Journal of Business Management, Entrepreneurship and Innovation, Volume 4, Issue 1, 2022, PP 20-35, ISSN 2707-8027

\section{BNET}

management practices. The theory is relevant as it shows how leadership behavior affects employee morale and eventually organizational performance.

\subsubsection{Kotter's Theory}

Kotter (1996) formulated Kotter's theory to assist in the proper management of change. Kotter acknowledged that procedural changes and why some organizations fail in the changing process might be due to incomprehensively covering some steps or completely ignoring them. The theory proposes an eight-step model that the author believes will result in long-lasting strategical change for the organization. The first step is creating a sense of urgency. Strategic communication is key here. This step involves the organization being aware that change is inevitable and be ready to embrace it. The second stage is forming a guiding coalition. This group of employees has bought into the idea of change, chosen by the organization to bring other employees on board the change ship. This is particularly effective in bringing employees on board with the changes. The third stage is developing an inspired vision. This speaks to the variables of strategic target setting which then forms the basis for strategic supervision. This stage tasks the change agents with formulating a clear vision for the change that is understandable by all other employees. The developed vision is then conveyed to all employees in the fourth stage. This stage also entails the integration of the new vision to all or most activities of the organization.

The fifth stage involves the organization's top management empowering other employees, 'change agents' with enacting the vision. Subsequently, the organization should create short term goals and record short term wins. This again supports the variable of strategic target setting and acts as a great motivation to both the management and employees as it is an indication that they are on the right track. In the seventh stage, Kotter (1996) opines that vision acceleration should be sustained. This entails the leadership not being blinded by short-term wins as a success in the change process. Kotter (1996) further states that the success of change is only achieved after the vision process has witnessed several wins. The final stage entails embedding within the culture and core of the organization. This entails changing the organization's values, structures, objectives, systems, and processes to fit the new changes. The Kotter theory further asserts that change is a step-by-step process that should be treated to ensure successful implementation. In most cases, adapting to changes leads to changes in other organizational aspects such as organizational values, structures, objectives, systems, and processes. The theory is relevant as it explains how Strategic change management practices, which are practices of corporate governance is critical to organizational performance.

\subsubsection{The Dynamic Capabilities Theory}

It was first postulated by Teece, Pisano, and Shuen (1997). Dynamic capabilities are stable and learned behavior patterns systematically generated by an organization and modified the way it operates to be more effective. To match the changes that take place in the turbulent environment, organizations are examined according to how they can build, integrate and configure their specific competencies either external and internal into new competencies. Teece, (2014), dynamic capability framework assumes organizations with smaller dynamic capabilities are outperformed by those with greater dynamic capabilities. This calls for organizations with operations in dynamic environment to regenerate, renew, reengineer continuously their external and internal organization specific capabilities so as to attain best performances. 
International Journal of Business Management, Entrepreneurship and Innovation, Volume 4, Issue 1, 2022, PP 20-35, ISSN 2707-8027

\section{BNET}

The theory supports the variables of corporate communication, strategic target-setting, and strategic resource allocation. By strategic communication, dynamic capability theory justifies how the management can approach and take communication to be a fundamental piece of managing and controlling the flow of activities, tasks, and information to align with the requirements of the changes in the operating environment. Dynamic capabilities theory supports the variable of strategic target setting since each of the intended outcome must be targeted for and positioned in a manner that would trigger efforts to achieve it. Dynamic capabilities theory supports the variable of strategic resource allocation since the achievement of desired performance goals requires the core skill of decision making.

Developing dynamic capabilities are hard since "they are tactic and are also embedded in a unique set of histories and relations of an organization." They reside in top management's leadership skills and managerial entrepreneurship in the organization and their managerial ability modify, implement, develop and design daily routines of the organization. Strong dynamic capabilities include leadership skills, technology, business models and processes required to effect high performance sensing, transforming and seizing the organization. Teece (2014) posits that those organizations having dynamic capabilities that are strong exhibit market and technological agility, they can also modify their business models and structures, maintain and differentiate superior processes and create new technologies so as to stay ahead of competitors and at pace with the market and in shaping and reshaping the market if need be. Empirically measuring dynamic capabilities is difficult since they are the underlying operational processes and the relationship between them and company performance. Measuring part of resource bundles or the processes and routines that are often distinctive to firms is also difficult (Vercic \& Vokic, 2017). The theory is applicable here because it guides the researcher in linking the dynamics of management decision and cations and its implications on organizational competitiveness and performance.

\subsection{Empirical Literature Review}

This provides an empirical review of existing literature relevant to this study. It is a collection of information on the adopted research methodologies, research objectives as well as the findings of such studies. The literature is useful in helping the researcher to predict the study' expected independent and dependent relationship and in designing the research instrument and methodology.

\subsubsection{Corporate Communication and Performance}

Mohamad, Bakar, Halim and Ismail (2014) sought to review existing literature on organizational performance and Corporate Communication Management (CCM). Research objectives were to establish how mission achievement and financial performance were impacted by corporate communication management. The reviewed literature revealed that corporate communication management had a positive association with firm performance. However, it isn't clearly established, the close corporate communication field like marketing and communication reveals a strong association. There was significant direct relationship between mission achievement (nonfinancial performance and corporate communication. Luo and Jiang's (2017) reviewed the aspect of internal corporate communication on organizational performance. The study tested the effect of over, optimal, and under- internal corporate communication to the prospects of organizational performance. Both over and under-internal communication were found to contribute negatively towards performance. Over-allocation was found to lead to wastage and lack of efficiency. Underallocation was found to be detrimental because it led to capacity issues and lower productivity. 
International Journal of Business Management, Entrepreneurship and Innovation, Volume 4, Issue 1, 2022, PP 20-35, ISSN 2707-8027

\section{$B=$}

Optimal internal communication was found to be the most suitable hence leading to better organizational performance. The study does not provide a methodological approach used to arrive at the findings. Ojwang (2018) reviewed the influence of corporate communication on Airtel Kenya's financial performance. He sought to examine the influence the firm's corporate communication on its financial performance. Descriptive survey was adopted, and data collected using questionnaires from a sample of 248 Airtel Kenya customers. Inferential and descriptive statistics were utilized in evaluating the gathered data. The analyzed study disclosed that corporate communication strategies had positively influenced firm's financial performance in the following ways: increase service uptake, growth in shareholder value, product purchase, awareness on Airtel service and products, and better customer service and loyalty.

\subsubsection{Strategic Supervision and Performance}

Makina \& Keng'ara (2018) did a study to find out what caused below daily target of 7,000 tonnes in Nzoia Sugar Company milling cane, what cause resistance to change, formulation, implementation and control of strategies. Secondary and primary data was used, data collection was by questionnaires. Descriptive statistics and multiple correlation were used for data analysis. The results indicated that $6.5 \%$ of managers resisted change while a high percentage $(67.7 \%)$ of resistance to change was from subordinates (Makina \& Keng'ara, 2018). The study recommended all stakeholders' involvement in strategy supervision, which should begin with strategy formulation, then strategy implementation and finally strategy control. All these are crucial in realizing desirable performance. However, the study did not factor in the variables being assessed by the current study.

A study by Kim \& Kim (2015) examined how organizational citizenship behaviors and task performance of employees are linked to moral competences of leaders and employees. organizational citizenship behaviors and task performance of employees are linked to competences of leaders and employees Kim \& Kim (2015). Based on 102 employee-supervisor pairs sample from South Korea's seven organizations, it was evident that organizational citizenship behaviors (OBs) towards leaders and task performance of employees associated positively with moral competences of leaders and employees. OCBs and task performance of employees' relationship with moral competences of leaders was partially mediated by Employees' psychological empowerment as anticipated. Psychological empowerment of employee association with moral competences of leaders was moderated by Person-supervisor fit (PS fit) in that compared to individuals lower in the PS fit, the ones higher had a stronger relationship. The suggestions perceived that leadership of the supervisor can contribute to organizational commitment, job satisfaction and employee well-being. The research, however, was carried out in Chinese firms and contextually, it may not apply correctly to Kenyan firms.

Finally, in a study done by Muhammad (2016), the research aimed at determining how employee performance at the North Sumatra Transportation Department in India was influenced by both partial supervisions, simultaneously supervision and discipline. All the 154 North Sumatra Transportation Department employees formed the study population, and a sample of 61 employees analyzed using Slevin formula. Documentation studies, interviews and questionnaire were used in data collection. The results indicated that performance of employees was positively and significantly influenced supervisory variable and work discipline variable and simultaneously supervision and work discipline significantly affect employee performance improvement. The 
International Journal of Business Management, Entrepreneurship and Innovation, Volume 4, Issue 1, 2022, PP 20-35, ISSN 2707-8027

\section{BMME}

study focused on how employee performance was influenced by supervision, while this study is about how performance is influenced by supervision.

\subsubsection{Strategic Target-setting and Performance}

Ogunyemi, Fasanmi \& Onunkun (2018) carried out a study to examine "the mediating roles of corporate goal setting and goal orientation in corporate ethical values and work attitudes of bank employees in Nigeria." Regression analysis and correlation coefficient were utilized. Results showed that Nigerian bank employees' work attitude is significantly contributed by corporate ethical values, target orientation and corporate target-setting's mediating roles in corporate ethical values' contribution to Nigerian bank employees' work attitude. The recommendation was that an organization sets attainable, specific targets and among employees foster performance goal orientation. The study's limitation lies in the fact that it focuses on employee performance whereas this focuses on overall performance of the firm.

A research study conducted by Bronkhorst, Steijn \& Vermeeren (2015) established that ample empirical research has indicated that using target setting increases individual performance level. It was revealed that "Goal congruence has a relation with employees' perception of empowerment, fairness allocating reward, leadership support and morale." From the findings, it can be noted that in increasing organizational effectiveness, target setting is a powerful means, and that productivity and performance of employees is enhanced by target-setting. Thus, organizational performance improvement would be as a result of a high employee performance level through appropriate target setting. The study's limitation is that it does not show the data methodology and data analysis method used in arriving at the findings. In a study by Teo and Kim (2016), a target setting conceptual model was developed by the duo researchers and its relationship with organization and employee effectiveness. In testing its reliability and validity using a qualitative research, three hypotheses were formulated. The sufficient evidence was provided by literature review and search for supporting the 3 hypotheses. In XYZ Singapore, an empirical study was undertaken to test the three hypotheses. Justifications for the research methodology were provided. A highlight on relevant ethical consideration in collecting data is also given. Results suggested that the hypotheses are evident in their organization and they are reliable and valid. Participants in the research interview had a unanimous concurrence that in the relationship, target settings play a role depicted in the conceptual model and that employee effectiveness is impacted hence improving organizational effectiveness. The study's limitation is that it focuses on employee and organizational effectiveness while the current study focuses on SACCO performance.

\subsubsection{Strategic Resource Allocation and Performance}

In a study compiled by Maduenyi et. al (2015), the aspect of allocating resources has been given much weight as it was crucial to organizational performance. The study tested the effect of over, optimal, and under-allocation of resources to the prospects of organizational performance. Both over and under-allocation were found to contribute negatively towards performance. Overallocation was found to lead to wastage and lack of efficiency. Under-allocation was found to be detrimental because it led to capacity issues and lower productivity. Optimal allocation of resources was found to be the most suitable level of allocation as it had little wastage and was thus efficient. The study does not provide a methodological approach used to arrive at the findings. 
International Journal of Business Management, Entrepreneurship and Innovation, Volume 4, Issue 1, 2022, PP 20-35, ISSN 2707-8027

BMED

In his study, Ndegwah (2017) did an analysis on "how strategic plans implementation in public secondary schools in Othaya and Mukurweini sub-counties of Nyeri County were influenced by rewards, and incentives, resources allocation, institutional policies and managerial skills." The findings indicated the need for budget development prioritization and resource allocation policies. A proposed priority for institution policies was established and training of management team on key skills enabling the strategy implementation. It was found that strategic plans implementation in schools was not influenced by financial incentives and rewards. The study examines implementation of strategic plans and not concerned with performance thus empirically and contextually different from the current study thus the measurement metrics may differ considerably. Elsewhere, Ombaka, Machuki \& Mahasi (2015) studied how water supply firms' strategy implementation in Mombasa was influenced by stakeholders, organizational resources, organizational culture and leadership. Questionnaires were issued to employees from 3 department who were chosen using stratified random sampling technique. The conclusion was that poor strategy implementation was as a result of interference from stakeholders, limited funds, inadequate human resource skills, poor guidance and leadership style from managers and lack of top management team commitment. The study is critiqued since it focuses on strategy implementation, whereas the current study looks at performance.

In a 2018 study by Mwai, Mulaa \& Katuse (2018) on how organizational effectiveness is influenced by available resources. Positivity was the philosophy of the research; descriptive and explanatory design were used. Registered NGOs were used as the population with project managers as the sample unit. The conclusion showed that the organization process' efficiency level is influenced by distribution of funds to the various strategic operations and activities and fundraising efforts. Process efficiency was influenced by staff empowerment. This shows that organizational effectiveness is significantly enhanced by organizational resources. organizational effectiveness achievement is significantly and positively influenced by organizational resources. It was established that organizational processes' efficiency is positively influences by fundraising efforts. The ability of organizations to their objectives and organizational strategy is positively influenced by resource distribution. Since the study recommended. Effective funds allocation thus enhancing success of productivity and performance of an organization, hence similar research needs to be undertaken while utilizing funding source as an a mediating variable to confirm if the results are different. The limitation of the study is that it studies organizational effectiveness while the current study focuses on performance.

\subsection{Research Methodology}

This study utilized descriptive research design. The design provides information on the phenomenon or a population's characteristics and answers the questions of how, where, when, what and who related with the problem under study. It is used in obtaining information about the current phenomena status for describing, "What exists" with respect to a situation's conditions or variables (Astalin, 2015). The justification behind the adoption the design was to provide a study plan permitting cause-and-effect accurate assessment of dependent and independent variables' relationships. The design was considered appropriate since the main objective was to assess how Kiambu County SACCOs' performance and strategic change management practices relate.

The study targeted top management in 14 Kiambu County SACCOs (according to SASRA annual supervision report of 2019). The unit of observation was 70 respondents i.e., five respondents from each of the selected SACCOs. The unit of observation comprised of departmental managers such 
International Journal of Business Management, Entrepreneurship and Innovation, Volume 4, Issue 1, 2022, PP 20-35, ISSN 2707-8027

BMED

as Retail Head, Corporate Affairs Head, Internal Audit Head, Operations Head and Head of Finance and Strategy or their equivalent.

In the study, the population of study was not sampled owing to the small number of participants. Therefore, a census study was adopted focusing on the employees with accurate information about the topic of study and in this case the respondents were Retail Heads, Corporate Affairs Heads, Internal Audit Heads, Operations Heads and Heads of Finance and Strategy or their equivalent. Both secondary and primary data was used. Primary data was collected using structured questionnaires. Questionnaire's advantage is that the questions for every responded are same thus ensuring uniformity. The Likert Scale represented items in the questionnaires. The questionnaires contained three sections each: the first section sought to establish the respondents' demographic data, the second section highlighted the strategic change management practices, while section three highlighted the measurement of organizational performance. The researcher engaged in field work which included seeking permission from respective SACCOs' Chief Executive Officers using the university's introduction letter and the approval to conduct research provided by National Commission for Science, Technology, and Innovation (NACOSTI). After the questionnaires were filled, the researcher coded and analyzed the data and stored the competed tools for future reference. In determining independent and dependent variables' relationship, multiple regression analysis was used in inferential statistics analysis. Regression of SACCO performance against various strategic change management practices of the organization was done. strategic alignment practices and SACCO's performance equation.

\subsection{Data Analysis Results}

This is used in examining each independent variable's effect on the dependent variable. The study utilized regression analysis to determine the impact of corporate communication, strategic supervision, strategic target setting and strategic resource allocation on organizational performance.

Table 1 Model Summary

\begin{tabular}{lrrrrrr}
\hline Model & \multirow{2}{*}{ R } & & R Square & $\begin{array}{l}\text { Adjusted R } \\
\text { Square }\end{array}$ & Std. Error of the Estimate & \\
\hline & 1 & $.719^{\text {a }}$ & 0.517 & 0.498 & 0.569 \\
\hline
\end{tabular}

\section{Source: Survey data, 2021}

From the model summary it was discovered that R Square was 0.517 . Implying that $51.7 \%$ of the variation in performance of the SACCOs was explained by corporate communication, strategic supervision, strategic target setting and strategic resource allocation.

ANOVA assess whether the relation between the variables is statistically significant. "If the model' significance level is greater than 0.05 then the model is not statistically fit to predict the dependent variable and if the level of significance is less than 0.05 the model is statistically fit to predict the dependent variable." Table 2 presents the findings from the study.

Table 2 ANOVA

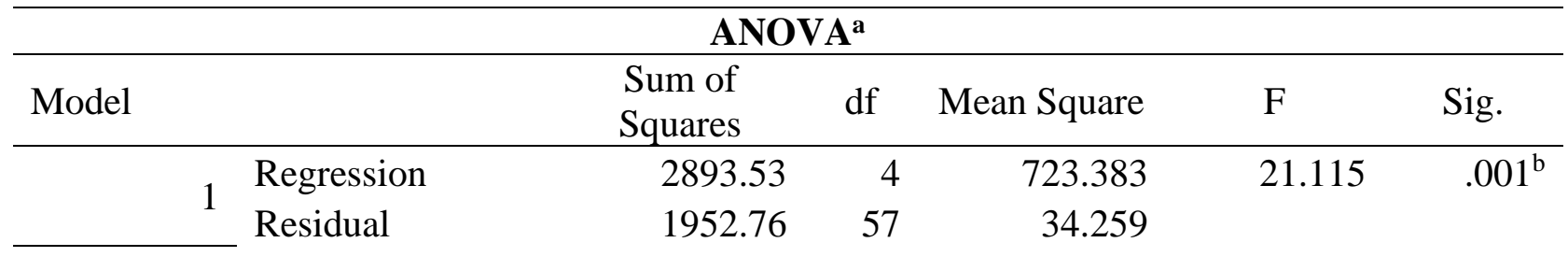


International Journal of Business Management, Entrepreneurship and Innovation, Volume 4, Issue 1, 2022, PP 20-35, ISSN 2707-8027

BMED

Total

4846.29

61

Source: (Survey data, 2021)

From the Anova table it was shown that the significance level for the model was 0.001 . This was lower than 0.05. This implies that the model fit with corporate communication, strategic supervision, strategic target setting, and strategic resource allocation is statistically significant in predicting organizational performance.

These coefficients help show the magnitude with which each independent variable have an influence on the dependent variable. Table 3 below has the findings.

Table 3: Regression Coefficients

\begin{tabular}{|c|c|c|c|c|c|}
\hline \multicolumn{6}{|c|}{ Coefficients $^{\mathbf{a}}$} \\
\hline \multirow[t]{2}{*}{ Model } & \multicolumn{2}{|c|}{$\begin{array}{l}\text { Unstandardized } \\
\text { Coefficients }\end{array}$} & \multirow{2}{*}{$\begin{array}{c}\text { Standardized } \\
\text { Coefficients } \\
\text { Beta }\end{array}$} & \multirow[t]{2}{*}{$\mathrm{t}$} & \multirow[t]{2}{*}{ Sig. } \\
\hline & B & Std. Error & & & \\
\hline \multirow{5}{*}{$\begin{array}{l}1 \text { (Constant) } \\
\text { corporate communication } \\
\text { strategic supervision } \\
\text { strategic target setting } \\
\text { strategic resource allocation }\end{array}$} & 0.379 & 0.641 & & 2.46 & 0.001 \\
\hline & 1.624 & 0.028 & 0.876 & 0.294 & 0.001 \\
\hline & 0.701 & 0.036 & 0.615 & 0.451 & 0.001 \\
\hline & 0.464 & 0.118 & 0.133 & 0.649 & 0.001 \\
\hline & 1.56 & 0.112 & 0.776 & 0.559 & 0.001 \\
\hline
\end{tabular}

Source: (Survey data, 2021)

\subsection{Conclusion and Recommendations}

The study concluded that corporate communication, strategic supervision, strategic target setting, strategic resource allocation and organizational performance positively related. The study recommends that the SACCOs top management adopts and trains its employees on effective resource management. This is in a bid to ensure that resource allocation is done in a way that is strategic and keeps on enhancing the SACCOs' performance. The study also recommends that the top Managers put measures that enable them to set strategic targets that are realistic and achievable to enable the SACCOs to realize performance improvement that is measurable. The study also recommends that the SACCOs implement measures that make supervision of employees easier as well as continually train their employees on what is expected of them from their roles so as to minimize the supervision of employees.

\section{References}

Abass, M. K., Munga, J. \& Were, E. (2017). The relationship between strategy implementation and performance in county governments of Kenya: A case study of Wajir County government. International Academic Journal of Human Resource and Business Administration, 2(3), 381-401.

Akter, S., Wamba, S. F., Gunasekaran, A., Dubey, R., \& Childe, S. J. (2016). How to improve firm performance using big data analytics capability and business strategy alignment?. International Journal of Production Economics, 18(2), 113-131.

Al-Kandi, I., Asutay, M. \& Dixon, R. (2015). Factors influencing the strategy implementation process and its outcomes: Evidence from Saudi Arabian banks. Journal of Global Strategic Management, 7(2), 5-15. 
International Journal of Business Management, Entrepreneurship and Innovation, Volume 4, Issue 1, 2022, PP 20-35, ISSN 2707-8027

BMED

Almansoori, S. (2019). Shaping the future through strategic change management framework in the UAE Law Enforcement Agency (Doctoral dissertation, University of Salford). Approaches. Nairobi: Africa Centre for Technology Studies press. approaches.

Astalin, P. K. (2015). Qualitative research designs: A conceptual framework. International Journal of Social Science and Interdisciplinary Research, 2(1), 118-124.

Blok, V., Hoffmans, L., \& Wubben, E. F. (2015). Stakeholder engagement for responsible innovation in the private sector: Critical issues and management practices. Journal on Chain and Network Science, 15(2), 147-164.

Bower, J. L. (2016). $6^{\text {th }}$ ed. Managing the resource allocation process. Boston: Harvard University, Graduate School of Business Administration.

Bronkhorst, B., Steijn, B., Vermeeren, B. (2015). Transformational leadership, goal setting, and work motivation: The case of a Dutch municipality. Review of Public Personnel Administration, 35, 124-145.

Danisman, S., Osuntas, S., and Karadag, E. (2015). The Effect of Leadership on Organizational Performance. In: Karadağ E. (eds) Leadership and Organizational Outcomes. Springer: Cham.

Durand, R., Grant, R. M., \& Madsen, T. L. (2017). The expanding domain of strategic management research and the quest for integration. Strategic Management Journal, 38(1), 4-16.

Engelbrecht, A.S., Heine, G. \& Mahembe, B. (2014) 'The influence of ethical leadership on trust and work engagement: An exploratory study', SA Journal of Industrial Psychology, 40(1), $1-9$.

Gerrish, Ed. (2015). "The Impact of Performance Management on Performance in Public Organizations: A Meta-Analysis." Public Administration Review 76(1):48-66.

Goyal, C., \& Patwardhan, M. (2018). Role of change management using ADKAR model: a study of the gender perspective in a leading bank organisation of India. International Journal of Human Resources Development and Management, 18(3-4), 297-316.

Greenwood, R., \& Hinings, C. R. (2017). Understanding strategic change: The contribution of archetypes. Academy of management Journal.

Gupta, M. (2016). An empirical study on fit between strategic human resource management and business strategy. International Journal of Management Research and Reviews, 6(2), 102.

Gweyi, M.O. (2014). Effects of financial Leverage on Financial Performance of Deposit Taking SACCOs in Kenya. International Journal of Academic Research in Accounting, Finance and Management Sciences, 4(2), 180-188.

Helfat, C. E., \& Martin, J. A. (2015). Dynamic managerial capabilities: Review and assessment of managerial impact on strategic change. Journal of Management, 41(5), 1281- 1312.

Hussain, S. T., Lei, S., Akram, T., Haider, M. J., Hussain, S. H., \& Ali, M. (2018). Kurt Lewin's change model: A critical review of the role of leadership and employee involvement in organizational change. Journal of Innovation \& Knowledge, 3(3), 123-127.

Implementation and Control. USA: Richard Irwin Publishers.

Isaboke, C. M. (2015). Influence of organization culture on strategy implementation in selected universities in Kenya. International Journal of Economics, Commerce and Management, III (9), 1-15.

Kafashpoor, A., Shakoori, N. and Sadeghian, S. (2016) Linking Organizational Culture, Structure, Leadership Style, Strategy, and Organizational Effectiveness: Mediating Role of Knowledge Management. Advanced Research in Economic and ManagementSciences (AREMS), 10, 158-172. 
International Journal of Business Management, Entrepreneurship and Innovation, Volume 4, Issue 1, 2022, PP 20-35, ISSN 2707-8027

\section{BME}

Karani, N. K. (2016). Strategic change management practices at National Bank of Kenya Ltd (Doctoral dissertation, University of Nairobi).

Kibicho, P. M. (2015). Determinants of Strategy Implementation Success in the Insurance Industry: A Survey of Insurance Companies in Kenya. International Journal of Business and Social Science, 6(4), 74-91.

Kim, S., Son, S. \& Yun, S. (2018), "Abusive supervision and knowledge sharing: the moderating role of organizational tenure", Personnel Review, 47(1), 22-38.

Kim, T. \& Kim, M. (2015). 'Leaders' moral competence and employee outcomes: The effects of psychological empowerment and person-supervisor fit', Journal of Business Ethics 112, $155-166$.

Kiptoo, J. K. \& Mwirigi, F. M. (2016). Factors That Influence Effective Strategic Planning Process in Organizations. IOSR Journal of Business and Management (IOSR-JBM), 16(6), 188195.

Kirui, F., Ndiao, D. O., \& Wasike, D. S. (2018). Strategy Implementation and Financial Performance of Finance Institutions in Kenya: A Case of Shelter Afrique. Journal of Strategic Management, 2(4), 21 - 36.

Kitonga, D., Bichanga, W., \& Muema, B. (2016). The role of determining strategic direction on not-for-profit organizational performance in Nairobi County in Kenya, International Journal of Scientific \& Technology Research, 5(5): 28-32.

Kitsios, F., \& Kamariotou, M. (2017). Strategic Change Management in Public Sector Transformation: The Case of Middle Manager Leadership in Greece. In Proceedings of BAM Conference 2017 (pp. 73-78).

Lemarleni, J. E., Ochieng, I., Gakobo, T. \& Mwaura, P. (2017). Effects of resource allocation on strategy implementation at Kenya Police Service in Nairobi County. International Academic Journal of Human Resource and Business Administration, 2(4), 1-26.

Luo, Y., \& Jiang, H. (2017). Effective public relations leadership in organizational change: A Journal of Communication Management, 19 (2), 118-132.

Maduenyi, S., Oke, A. O., Fadeyi, O., \& Ajagbe, A. M. (2015). Impact of Organisational Structure on Organisational Performance. Journal of International Business Management 14(4), 354-358.

Mailu, R. N., Ntale, J. F. \& Ngui, T. K. (2018). Strategy implementation and organizational performance in the pharmaceutical industry in Kenya. International Academic Journal of Human Resource and Business Administration, 3(2), 33-47.

Maina, M. W. (2019). The Influence of Strategic Leadership on Financial Performance of Savings and Credit Co-operative Societies in Nairobi City County, Kenya (Doctoral dissertation, University of Nairobi).

Makadok, R., Burton, R., \& Barney, J. (2018). A practical guide for making theory contributions in strategic management. Strategic Management Journal, 39(6), 1530-1545.

Makina, I. \& Keng'ara, R. (2018). Managing Strategic Change of an Organization's Performance: A Case Study of Nzoia Sugar Company, Kenya. Universal Journal of Management 6(6), 198-212.

Mango, D. R. (2017). Determinants of Successful Strategy Implementation: A Survey of Selected Public Schools in South Africa. International Journal of Business and Management Invention, 3(1), 41-46. 
International Journal of Business Management, Entrepreneurship and Innovation, Volume 4, Issue 1, 2022, PP 20-35, ISSN 2707-8027

\section{BMED}

Matata, D. J. and Wafula, M. K. (2015). Effects of Quality Management Systems on Performance of Kenya Ports Authority. International Journal of Scientific and Research Publications (IJSRP), 5(5).

Mbaka, R.M. \& Mugambi, F. (2015). Factors affecting successful strategy implementation in the Water Sector in Kenya, Journal of Business and Management, 16(7), 61-68.

Mohamad, B., Bakar, H. A., Halim, H., \& Ismail, A. R. (2014). Corporate Communication Management (CCM) and organisational performance: A review of the current literature, conceptual model and research propositions. Procedia-Social and Behavioral Sciences, 15(5), 115-122.

Momanyi, H., Senaji, T. A. \& Were, E. A. (2018). An assessment of factors affecting strategic implementation in devolved government units in Kenya: Case of Nairobi City County. International Academic Journal of Human Resource and Business Administration, 3(2), 339-359.

Mugenda, O. and Mugenda, A. (2013). Research methods: Qualitative \& Quantitative. Nairobi, Acts Press.

Muhammad Irfan Nasution (2016). The Influence of Supervision and Work Discipline on Performance of State Civil Apparatus, Proceeding 3rd Sriwijaya Economics, Accounting, and Business Conference, 1(1).

Mwai, G. M., Mulaa, J. \& Katuse, P. (2018). Influence of Organizational Resources on Organizational Effectiveness. AJIBM, 8(6).

Mwangi, J. K., Nyachwaya, Z. O., \& Cheruyoit, R. K. (2015). Effect of Corporate Governance Practices on Financial Performance of SACCOs in Kericho Municipality. Journal of Economics and Finance, 6(3), 57-75.

Ndegwah, D.M. (2017) Factors Affecting the Implementation of Strategic Plans in Public Secondary Schools in Nyeri County, Kenya. International Review of Management and Business Research, 3, 993-1002.

Neill, M.S. (2015). Beyond the C-Suite: Corporate Communications' Power \& Influence.

Njoroge, J. K., Machuki, V. N., Ongeti, W. J., \& Kinuu, D. (2015). The Effect of strategy Implementation on Performance of Kenya State Corporations. Prime Journal of Business Administration and Management (BAM), 5(9), 1913-1922.

Nyaga, D. K. \& Gakobo, J. (2017). Effect of quality management practices on organizational performance of savings and credit co-operatives in Kirinyaga County, Kenya. International Academic Journal of Human Resource and Business Administration, 2(4), 306-328.

Nzyoki, J. M. \& Mingaine, L. (2015). Factors Influencing Implementation of Strategic Plans in the Municipal Council of Machakos, Kenya. International Journal of Art \& Humanity Science, 2(3), 11-21.

Ocasio, W., Laamanen, T., \& Vaara, E. (2018). Communication and attention dynamics: An attention-based view of strategic change. Strategic Management Journal, 39(1), 155-167.

Odita, A. \& Bello, A. (2015). Strategic intent and organizational performance: A study of Banks in Asaba Delta State in Nigeria, Information and Knowledge Management, 5(4): 60-71.

O'Dwyer, L. M. \& Bernauer, J. A. (2014). Quantitative Research for a Qualitative Researcher. SAGE Publication, Inc: London, UK.

Ogaja, C. K. \& Kimiti, G. K. (2016). Influence of Strategic Leadership on Implementation of Tactical Decisions in Public Universities in Kenya. International Journal of Science and Research (IJSR), 5(1), 681-689. 
International Journal of Business Management, Entrepreneurship and Innovation, Volume 4, Issue 1, 2022, PP 20-35, ISSN 2707-8027

\section{BMED}

Ogunyemi A., O. \& Fasanmi, S. S. \& Onunkun Olubunmi (2018). Mediating Roles of Corporate Goal-Setting, Goal-Orientation and Corporate Ethical Values on Work Attitudes of Bank Employees. Business and Management Research, 7(2),20-34

Ojwang, F. (2018). The influence of corporate communication on financial performance of Airtel Kenya. Unpublished MBA Project, Daystar Unversity.

Ombaka, B., Machuki, V.N. and Mahasi, J. (2015) Organizational resources, external environment, innovation and firm performance: A Critical Review of Literature. $D B A$ Africa Management Review, 5(2), 60-74.

Omwenga, J. (2019). The effect of Corporate Governance on Financial Performance of Large Tier Savings and Credit Cooperatives Societies in Kenya. DBA Africa Management Review, 5(2), 63-73.

Pearce, A. J. \& Robinson B. R. (2017). Strategic Management: Formulation, Public Relations Review, 4(3), 885-893.

Rainey, H. G., \& Jung, C. S. (2015). A conceptual framework for analysis of goal ambiguity in public organizations. Journal of Public Administration Research and Theory, 2(5), 71-99.

Ruth, K. (2017). Factors influencing implementation of strategic plans at Amatsi water Services Company in the county Government of Vihiga, Kenya. The International Journal of Business \& Management (ISSN 2321-8916).

Selvam, M., Gayathri, J., Vasanth, V., Lingaraja, K., \& Marxiaoli, S. (2016). Determinants of firm performance: A Subjective Model. Int'l J. Soc. Sci. Stud., 4(3), 90-102.

Shields, P. M. \& Rangarajan. (2013). A Playbook for Research Methods: Integrating Conceptual Frameworks and Project Management. Cambridge, MA: MIT Press.

Simon, C., \& Tagliabue, M. (2018). Feeding the behavioral revolution: contributions of behavior analysis to nudging and vice versa. Journal of Behavioral Economics for Policy, 2(1), 9197.

Taouab, O., \& Issor, Z. (2019). Firm performance: Definition and measurement models. European Scientific Journal, 15(1), 93-106.

Teece, D. (2014). A dynamic capabilities-based entrepreneurial theory of multinational enterprise. Journal of International Business Studies, 4(5), 8-37.

Teo, T. C., \& Kim, C. P. (2016). The impact of goal setting on employee effectiveness to improve organisation effectiveness: Empirical study of a High-Tech Company in Singapore. Journal of Business \& Economic Policy, 3(1), 23-34.

Torres, R., Sidorova, A., \& Jones, M. C. (2018). Enabling firm performance through business intelligence and analytics: A dynamic capabilities perspective. Information \& Management, 55(7), 822-839.

Verčič, A. T., \& Vokić, N. P. (2017). Engaging employees through internal communication, Walliman N. (2017). Research Methods: The Basics. $5^{\text {th }}$ edition. London: Routledge.

Wiedner, R., Barrett, M., \& Oborn, E. (2017). The emergence of change in unexpected places: Resourcing across organizational practices in strategic change. Academy of Management Journal, 60(3), 823-854.

This is an open-access article published and distributed under the terms and conditions of the (c) (7) \&) Creative Commons Attribution 4.0 International License of United States unless otherwise stated. Access, citation and distribution of this article is allowed with full recognition of the authors and the source. Copyright, content ownership and liability for content herein remain with the authors. 